\section{Etiological Factors and Evolution of Intracranial Hemorrhage in Term New-borns}

Lucas Hernández J*, Martínez Antón $\mathbf{J}$ and Urda Cardona A

Department of Pediatrics, Maternal and Child Hospital of Málaga, Spain

\begin{abstract}
Background: Intracranial hemorrhage is an uncommon but important cause of morbidity and mortality in term newborns of unknown incidence. Because of this, it is necessary to analyze and describe the etiological factors and symptomatology of presentation to the end of extending the knowledge that allows us to adapt the strategy and reduce diagnostic delay, as well as the development of possible neurological sequelae.
\end{abstract}

Methods: Retrospective study of term neonates diagnosed of intracranial hemorrhage in the first 28 days of life in a third level hospital between January 2008 and December 2015.

Results: Thirty one term newborns with intracranial hemorrhage were identified, with a mean age of diagnosis of 3.4 days of life. In 16/31 there was not obstetrical history of interest. Cesarean section was carried out in 13/31 and instrumental delivery in $6 / 31$. The clinical manifestations included seizures in $10 / 31$ and apnea in $7 / 31$. In all cases, the first neuromaging test made was the brain ultrasound and at the time of diagnosis, 13/31 presented anemia and $3 / 31$ thrombocytopenia. The most frequent type of intracranial hemorrhage was the intraparenchymal hemorrhage in 10/31 cases and bilateral hemispheric location was found in 14/31. In 14/31 the etiology was not identified and hypoxic-ischemic encephatologhy was the most common cause in $8 / 31$. Only $1 / 31$ case required urgent surgical intervention, $4 / 31$ newborns died and up to the time of study, $5 / 31$ have presented moderate-severe psychomotor delay and $3 / 31$ partial symptomatic epilepsy.

Conclusion: In our series hypoxia and/or dystocia were the factors most frequently associated with the development of intracranial hemorrhage and seizures, apnea and anemia were the more common signs of presentation. Intraparenchymal hemorrhage was the most common variety and lower psychomotor delay was observed until the time of the study in relation to the literature.

Keywords: Intracranial hemorrhage; Term new-borns; Neurologic outcomes

\section{Introduction}

Intracranial hemorrhage ( $\mathrm{ICH}$ ) is defined as the pathological accumulation of blood within the cranial vault. Neonatal cerebrovascular accidents have classically been reported in the literature to bleeding events related to preterm birth, intraventricular hemorrhage being the most common variety in this age range [1].

However, ICH in term newborns is relatively rare, its incidence remains unknown [2], and has a different location, etiology, clinical presentation and neurological prognosis. There have been described several risk factors that relate to their appearance in the term newborn, including dystocia, prolonged duration of labor, fetal weight and coagulation disorders, among others [3,4].

Early detection of these injuries may allow treatment, prevention of further injury, family counseling and neurodevelopmental assessment, but the diagnosis can be difficult due to the variety of clinical forms of presentation.

The aim of this study is to analyze the etiological factors, evolution and neurological prognosis of term new-borns affected by intracranial hemorrhage and epidemiological data associated with our series, in order to understand better the clinical characteristics of these patients and avoid prolonged diagnosis.

\section{Material and Methods}

We performed a retrospective study of term infants (gestational age $\geq 37$ weeks) diagnosed of ICH in the first 28 days of life in a hospital of a high income country, the Maternal and Child Hospital of Malaga, between January 2008 and December 2015.

Each case was analyzed in relation to gestational age, obstetric history and type and instrumentalization of delivery and we have also recorded the clinical, analytical data and neuroimaging test performed, which is the basis for diagnosis and classification according to the location of intracranial hemorrhage.

In turn, etiology, evolution and neurologic outcomes of patients with these injuries until the time of the study have been analyzed by clinical follow-up in our hospital, in order to find associated prognostic factors.

\section{Results}

During the study period 45,706 infants were born alive and 31 met the inclusion criteria, because they were full-term newborns and were diagnosed of $\mathrm{ICH}$ in the first 28 days of life, which is an incidence of 6-7/10,000 live births, with a gestational age mean of 38.9 weeks $(1.3$ SD) and with a slight predominance of males in $18 / 31$ cases. Birth

*Corresponding author: Javier Lucas Hernández, Division of Pediatric Neurology, Maternal and Child Hospital of Málaga, Avenida Arroyo de los Ángeles, s/n CP: 29011, Málaga, Spain, Tel: 0034666676806; E-mail: jlucashe@gmail.com

Received July 01, 2016; Accepted July 21, 2016; Published July 29, 2016

Citation: Hernández JL, Antón JM, Cardona AU (2016) Etiological Factors and Evolution of Intracranial Hemorrhage in Term New-borns. J Pediatr Neurol Med 1 : 113. doi: 10.4172/2472-100X.1000113

Copyright: @ 2016 Hernández JL, et al. This is an open-access article distributed under the terms of the Creative Commons Attribution License, which permits unrestricted use, distribution, and reproduction in any medium, provided the original author and source are credited. 
weights mean was $3,153 \mathrm{~g}$ (583.8 SD); $5 / 31$ had a birth weight of $\leq$ p5-p10 and 5/31, $\geq$ p90-p95. In the vast majority of cases, 30/31 were controlled pregnancies and $16 / 31$ did not present an obstetric history of interest (Table 1).

$13 / 31$ neonates were born by caesarean section and $6 / 31$ by instrument-assisted vaginal delivery, in $4 / 6$ by forceps and $2 / 6$ by vacuum, so $12 / 31$ were born by eutocic delivery. Regarding the Apgar scores at 1 minute and 5 minutes, 10/31 had a score $<7$ and 8/31, <7, respectively.

The mean age at diagnosis was 3.4 days of life, with a range 1-13 days of life. In relation to the symptoms of presentation, 10/31 presented seizures, $7 / 31$ apnea and 2/31 multiorgan failure, requiring mechanical ventilation connection 13/31 patients. At diagnosis, 13/31 presented in analytical control blood hemoglobin $\leq 15 \mathrm{~g} / \mathrm{dL}$ and $3 / 31$ thombocytopenia of $\leq 100.000$ platelets $/ \mathrm{mm}^{3}$. In all cases, the first neuroimaging test carried out was brain ultrasound, requiring computed tomographic (CT) 5/31 cases and magnetic resonance (MRI) $19 / 31$ for a greater characterization of bleeding and for monitoring it over time.

Intraparenchymal hemorrhage was the most common type in 10/31 newborns (Table 2). In 4/31 cases, two types of bleeding were found: Intraparenchymal and subarachnoid hemorrhages were the most frequent association in $2 / 31$ cases. The hemorrhage was bilateral in $14 / 31$ and 9/31 had left hemispheric involvement exclusively.

The etiology of ICH was not identified in 14/31 patients and in the other cases, hypoxic-ischemic encephalopathy was the most common cause in $8 / 31$ (Table 3 ).

\begin{tabular}{|c|c|}
\hline OBSTETRIC HISTORY & NUMBER OF CASES \\
\hline Gestational hypertension & $4 / 31$ \\
\hline Gestational diabetes & $2 / 31$ \\
\hline Multiple pregnancy & $1 / 31$ \\
\hline Uterine rupture & $1 / 31$ \\
\hline Plancetal abruption & $1 / 31$ \\
\hline Toxic consumption & $1 / 31$ \\
\hline No interest & $16 / 31$ \\
\hline
\end{tabular}

Table 1: Obstetric history of term newborns with $\mathrm{ICH}$.

\begin{tabular}{|c|c|}
\hline TYPE OF ICH & NUMBER OF CASES \\
\hline Intraparenchymal hemorrhage & $10 / 31$ \\
\hline Subependymal hemorrhage & $8 / 31$ \\
\hline Intraventricular hemorrhage & $2 / 31$ \\
\hline Subdural hemorrhage & $2 / 31$ \\
\hline Subarachnoid hemorrhage & $2 / 31$ \\
\hline Cerebellar hemorrhage & $2 / 31$ \\
\hline Epidural hemorrhage & $1 / 31$ \\
\hline
\end{tabular}

Table 2: Types of $\mathrm{ICH}$ in term new-borns.

\begin{tabular}{|c|c|}
\hline ETIOLOGY OF ICH & NUMBER OF CASES \\
\hline Hypoxic-ischemic encephalopathy & $8 / 31$ \\
\hline Early-onset sepsis & $3 / 31$ \\
\hline Traumatic brain injury & $2 / 31$ \\
\hline Hemorrhagic disease of the newborn & $1 / 31$ \\
\hline Acute liver failure & $1 / 31$ \\
\hline Neonatal hemochromatosis & $1 / 31$ \\
\hline Congenital heart defects & $1 / 31$ \\
\hline
\end{tabular}

Table 3: Etiology of $\mathrm{ICH}$ in term new-borns.

\begin{tabular}{|c|c|}
\hline NEUROLOGIC OUTCOMES & NUMBER OF CASES \\
\hline Moderate-severe psychomotor delay & $5 / 31$ \\
\hline Symptomatic partial epilepsy & $3 / 31$ \\
\hline Ventriculomegaly & $2 / 31$ \\
\hline Right-sided hemiparesis & $1 / 31$ \\
\hline Sixth cranial nerve palsy & $1 / 31$ \\
\hline Normal neurodevelopmental & $15 / 31$ \\
\hline
\end{tabular}

Table 4: Neurologic outcomes of newborns with $\mathrm{ICH}$.

Neurosurgical intervention was just required in $1 / 31$ patient who had an association of intraventricular and intraparenchymal hemorrhages, to evacuate them and place a ventriculoperitoneal shunt valve.

The average hospital stay was 14.5 days with a range of 2-78 days.

With regard to the neurologic outcomes, $4 / 31$ patients died and until the moment of the study, 5/31 had presented a moderate-severe psychomotor delay and 3/31 a symptomatic partial epilepsy during follow-up (Table 4). Besides, 4/6 new-borns with instrument-assisted vaginal delivery had normal neuro-developmental outcomes.

In addition, we performed an analysis to determine the association of dystocia, hypoxic-ischemic encephalopathy, seizures as a first clinical manifestation and intraparenchymal location of the bleeding with different neurologic outcomes and we obtained a statistically significant result for the presence of intraparenchymal hemorrhage and the development of symptomatic partial epilepsy, with an OR 4.02, 95\% CI (1.06 to 6.98 ) with $\mathrm{p}<0.05$, observed not statistically significant in the other parameters.

\section{Discussion}

ICH is a heterogeneous disorder with a nonspecific clinical presentation, variable etiology and leads to the appearance of significant neurological sequelae.

Instrument-assisted vaginal delivery place term newborns at increased risk for the development of ICH [3], because during the process there are sudden changes in cerebral blood pressure that contribute to the breakdown of the immature capillary-venous junction of the germinal matrix [5].

Of the 31 cases of our study, 19/31 were born by means of dystocia delivery (caesarean section or instrumental delivery) and it suggests that the realization of this type of delivery carries an increased risk of development of ICH, as described by other studies previously performed $[2,4]$, although some of them [6] argue that the type of delivery does not seem to be the most important risk factor and must take into account other perinatal events, such as the presence of previous placenta, placental abruption and uterine rupture, obtaining in our series only one case of the latter two, respectively.

A low score on the Apgar test can also be a marker of ischemic injury and/or bleeding in new-borns [3,4,6]. 10/31 cases in our series had a score $<7$ at one minute and $8 / 31<7$ at $5 \mathrm{~min}$, although normal Apgar scores do not rule out the possibility of neonatal intracranial hemorrhage, since $11 / 31$ presented a score of 9 and 10 at $1 \mathrm{~min}$ and $5 \mathrm{~min}$, respectively and the mean age at diagnosis was 3.4 days of life.

The symptoms of presentation of ICH depend on their location and severity and they are very unspecific in this age range. Our results are consistent with literature $[4,6-8]$, because seizures were the most common symptoms of presentation. 
Other risk factors, such as anemia, thrombocytopenia and coagulation disorders have been reported in other studies [2,3]. In hours, $13 / 31$ showed hemoglobin $\leq 15 \mathrm{~g} / \mathrm{dL}$ and 3 of these 13 new-borns, associated thrombocytopenia $\leq 100.000$ platelets $/ \mathrm{mm} 3$, so the finding of anemia has to force us to consider the presence of an intracranial hemorrhage. The existence of thrombocytopenia was low in our series, unlike other series in which it was the most important predictor of ICH [3]. In turn, 11/31 showed a prolonged prothrombin time (PT) that can indicate vitamin $\mathrm{K}$ deficiency and only in two cases, deficiency of others factors were found, one of hemorrhagic disease of the newborn with factor IX decreased and other one of acute liver failure with factors V, VII and X deficiency, that indicates that the incidence of coagulation disorders was low, in contrast with other studies [2].

In terms of neuroimaging, as described in other series of cases, brain ultrasound was the most employed test for diagnosis $[2,4,9,10]$, and CT and MRI $[11,12]$ were used to define more precisely the injuries, especially the last one for the hemorrhage evolution [13].

Intraparenchymal hemorrhage was the most common variety in our series; in 10/31 cases it appeared exclusively and in 4/31 it was associated with other bleeding, which differs from other studies, in which subdural hemorrhage was the type more common in term newborns $[4,6,14,15]$.

As described in other studies, in many cases, in 14/31, the etiology of ICH was not identified [8] and management was conservative in most of them [4].

As a result of ICH, 4/31 patients died, of which 3 had intraparenchymal involvement, and so far the study, 15/31 of diagnosed patients had a strictly normal neurological development during followup, 5/31 a moderate-severe encephalopathy ( $2 / 5$ with intraparenchymal involvement) and $3 / 31$ a symptomatic partial epilepsy (3/3 with intraparenchymal hemorrhage), which contrasts with other series, in which the incidence of neurological sequelae is higher $[2,4,9,16,17]$ and they were associated in most cases with the presence of subarachnoid hemorrhage.

Limitations of our review include that it is a retrospective study in which we found a small number of cases because of the low incidence of ICH in term new-borns and also we got a large number of them with not associated risk factors, so it would be appropriate to develop a multicentre study to provide other factors not detected in our series.

In conclusion, hypoxia and/or dystocia were the factors most frequently associated with ICH in term newborns in this study and early seizures, apnea and anemia were the most common signs of presentation, so their presence should alert physicians to the possibility of ICH in order to avoid a delay in diagnosis. Although intraparenchymal hemorrhage was the most common variety and carries an increased risk of mortality and development of symptomatic partial epilepsy, about half of the cases of our series presented a normal neurological development until the time of the study. Therefore a more intensive and lengthy follow-up might be considered to determine possible disturbances in attention, learning or behavior.

\section{References}

1. Vara OL, de Paula A, Simón MH, Musa M, Rodríguez JJ (2006) Hemorragia intracraneal en el recién nacido a término. Rev Ciencias Médicas 10.

2. Gupta SN, Kechli AM, Kanamalla US (2009) Intracranial hemorrhage in term new-born: Management and outcomes. Pediatr Neurology 2009 40: 1-12.

3. Jhawar BS, Ranger A, Steven D, Del Maestro RF (2003) Risk factors for intracranial hemorrhage among full-term infants: A case-control study. Neurosurgery 52: 581-590.

4. Brouewr A, Groenendaal F, Koopman C (2010) Intracranial hemorrhage in fullterm newborns: A hospital-based cohort study. Neuroradiology 52: 567-576.

5. Smith C (2006) Intracranial haemorrhage in infants. Current Diagnostic Pathology 12: 184-190.

6. Ou-Yang M, Huang C, Huang H, Chung M, Chen C, et al. (2010) Clinical manifestations of symptomatic intranial hemorrhage in term neonates: 18 years of experience in a medical center. Pediatr Neonatal 51: 208-213.

7. Huang $\mathrm{AH}$, Robertson RL (2004) Spontaneous superficial paranchymal and leptomeningeal hemorrhage in term neonates. AJNR Am J Neuroradiol 25:469475 .

8. Sandberg DI, Lamberti M, Drake JM, Humphreys RP, Rutka JT (2001) Spontaneous intraparenchymal hemorrhage in full-term neonates. Neurosurgery 48: 1042-1049.

9. Martínez JL, Díaz R, Sánchez E (2009) Accidente vascular encefálico en recién nacidos de término y pretérmino tardíos. Rev Chil Pediatr 80: 54-59.

10. Huisman T (2005) Intracranial hemorrhage: ultrasound, CT and MRI findings. Eur Radiol 15: 434-440.

11. Wezel G, Leijser LM, Bruine FT, Steggerda SJ, van der Grond J, et al. (2009) Magnetic resonance imagign of the brain in new-born infants: practical aspects. Early Human Development 85: 85-92.

12. Sirgiovanni I, Avignone S, Groppo M, Bassi L, Passera S, et al. (2014) Intracranial haemorrhage: An incidental finding at magnetic resonance imaging in a cohort of late pre-term and term infants. Pediatr Radiol 44: 289-296.

13. Khan IA, Wahab S, Khan RA, Ullah E, Ali M (2010) Neonatal intracrania ischemia and hemorrhage: Role of cranial sonography and CT scanning. $J$ Korean Neurosurg Soc 47: 89-94.

14. Rooks VJ, Eaton JP, Ruess L, Petermann GW, Keck-wherley J, et al. (2008) Prevalence and evolucion of intracranial hemorrhage in asymptomatic term infants. Rooks 29: 1082-1089.

15. Looney CB, Smith JK, Merck LH, Wolfe HM, Chescheir NC, et al. (2006) Intracranial hemorrhage in asymptomatic neonates: Prevalence on MR images and relationship to obstetric and neonatal risk factors. Radiology 42: 535-541.

16. Jordan LC, Kleinman JT, Hillis AE (2009) Intracerebral hemorrhage volume predicts poor neurologic outcome in children. Stroke 40: 1666-1671.

17. Elchalal U, Yagel S, Gomori JM, Porat S, Beni-Adani L, et al. (2005) Fetal intracranial hemorrhage (fetal stroke): Does grade matter? Ultrasound Obstet Gynecol 26: 233-243. 